\title{
Research on the Training Model of Visual Communication Professionals Based on Knowledge Conversion Model
}

\author{
Zhi Zi \\ Department of Visual Communication Design, School of Art and Design, Fuzhou Foreign \\ Languages and Foreign Trade College Fuzhou, Fujian 350202
}

Keywords: Knowledge transformation model; visual communication specialty; personnel training

\begin{abstract}
In view of the current situation of art design education, this paper studies the construction mode of visual communication design specialty, constructs the training mode of talents according to the actual needs of society, and puts forward the innovation of visual communication specialty personnel training based on traditional graphic design personnel training and knowledge transformation model. It breaks through the "linear" deductive relationship from theory to practice, stresses that knowledge transformation should be incorporated into the construction of a new talent cultivation model in the process of talent cultivation, and strives to cultivate visual communication design professionals based on knowledge transformation model.
\end{abstract}

The major of visual communication design is an important part of higher art education. The training mode of visual communication design professionals based on knowledge transformation plays a leading role in personnel training, which is a kind of construction and management of personnel training process. The training mode of innovative talents based on knowledge transformation is the real way for universities to carry out teaching activities and related professional work of visual communication design education. Guidance basis.

\section{Visual communication design talents demand}

In today's rapidly changing information society, with the increasingly important influence of social needs of related industries, innovative visual communication design professionals, namely, familiar with industry background, enterprise norms and market operation process, have strong creative thinking ability, design performance ability, skilled mastery of modern digital design and production. The proportion of talent demand tends to be top-notch for the technical comprehensive skill-based visual communication design professionals. At present, the training mode of visual communication design professionals in domestic universities is different. No matter the quantity, scale or quality specifications, there is a certain gap with the actual needs of the new cultural and creative industries, which has become one of the important factors restricting the development of cultural and creative industries and meeting the needs of talents. On the macro level, education and 
demand are "dislocated", while on the micro level, the work system of visual communication design is neglected in personnel training. How to construct the professional construction mode and personnel training mode and its operation mechanism suitable for the training of visual communication design talents has become the top priority. As shown in the following figure:

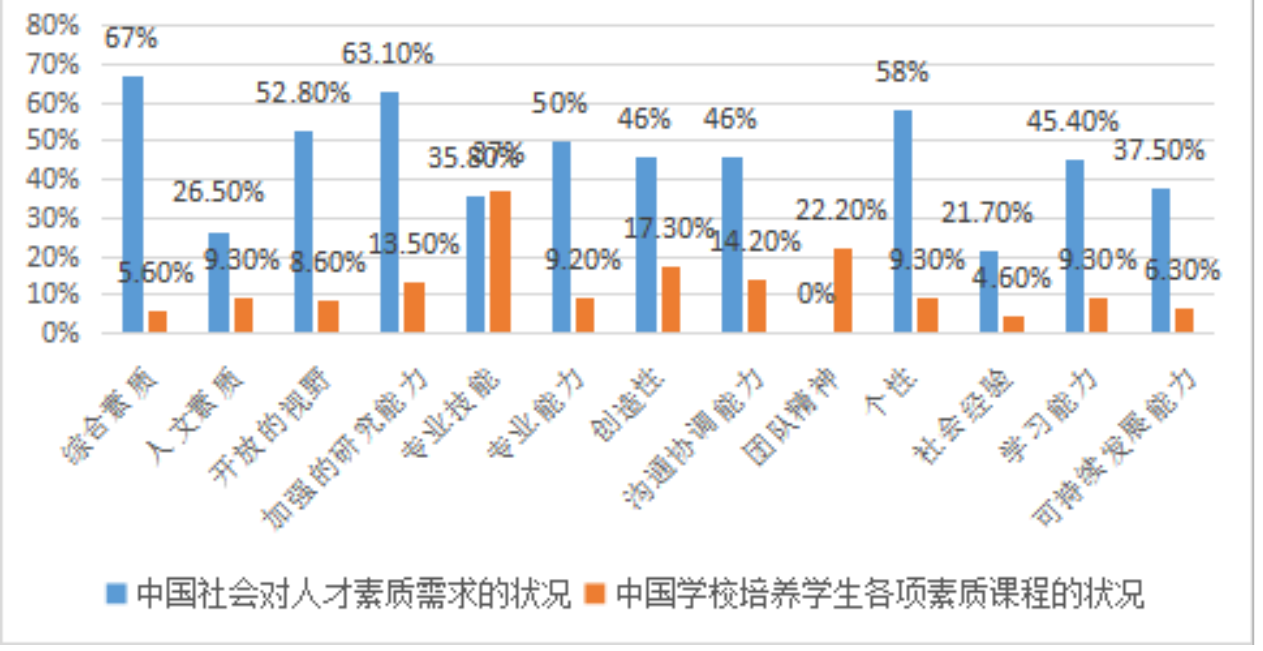

Figure 1. Social Needs and Personnel Training in China

\section{Training of visual communication design talents}

At present, the domestic art colleges and universities have undergone tremendous changes and unprecedented development speed. Behind the achievements, there are also some problems in the cultivation of art professionals. In order to achieve better results and achieve more lasting development, it is necessary to seriously solve these problems and study the key of personnel training, including education concept, training objectives, teaching content and so on. As shown in the following figure:
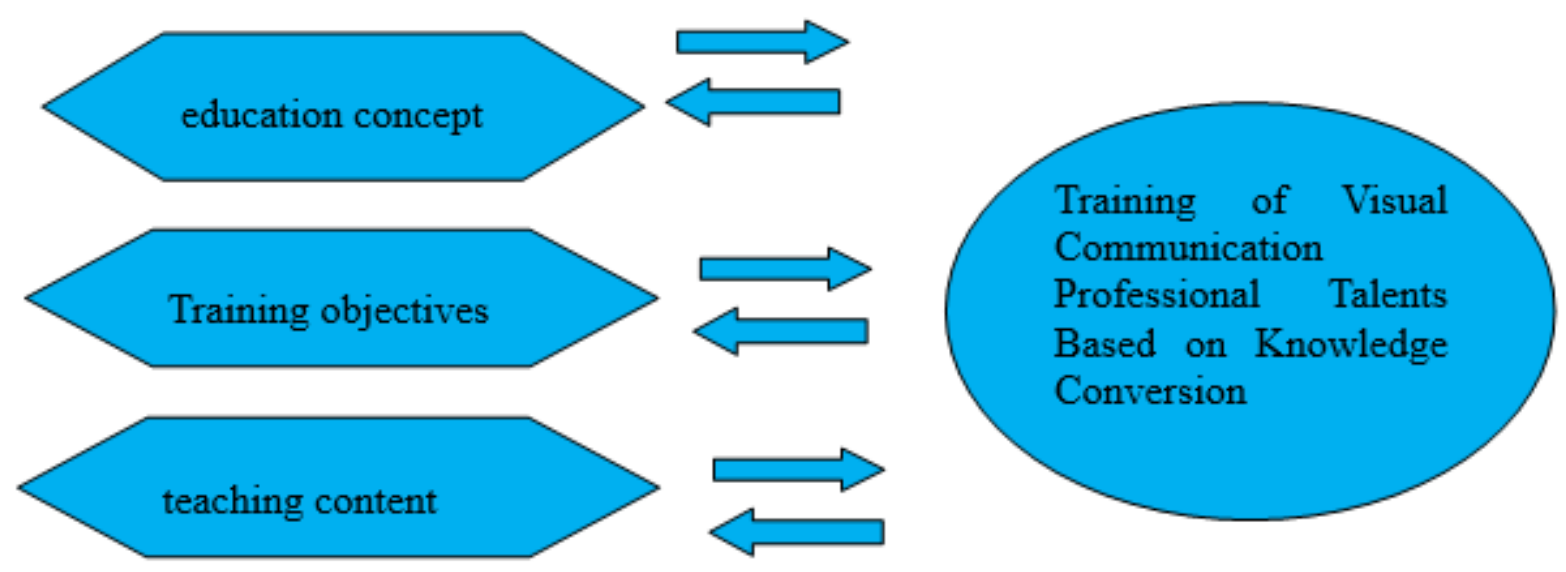

Figure 2. Training of Visual Communication Professionals Based on Knowledge Conversion

\subsection{Education concept}

Visual communication design has the characteristics of artistic and technical integration, so the cultivation of compound talents needs to constantly establish and improve scientific education concepts. That is, the concept of quality education, the concept of knowledge integration and the 
concept of innovative education. Modern educational concept holds that the mode of talent cultivation should be a highly unified one of knowledge education, ability cultivation and comprehensive quality shaping, and its core is through comprehensive quality shaping. The cultivation of visual communication design talents is a systematic and social engineering in higher art education. The main feature of the training is the interdisciplinary integration of science and technology. It involves many fields such as art, science and technology, social environment and so on. The cultivation of talents should embody the characteristics of integration and internationalization in the framework of knowledge. Visual communication design education should realize the transformation from imparting knowledge to emphasizing the cultivation of talents' innovative ability. In the education of visual communication design specialty, we should pay attention to the cultivation of creative thinking ability and creative ability of talents according to the characteristics of subjects and the advantages of quantitative training.

\subsection{Training objectives}

At present, the major of visual communication design has been set up in domestic colleges and universities according to social development. How to achieve effective professional positioning, establish brand as soon as possible, avoid the weakness of identical personnel training positioning and lack of personality is the key problem to be solved for the major of visual communication design to base itself on society and train useful talents for the industry. The solution lies in, first of all, according to the vision communication design professionals demand prospects, forward-looking positioning, to determine the goal of personnel training. Secondly, according to the different types of professional colleges and universities, deferentially positioned. Thirdly, according to the development of regional economy, we should make a distinctive orientation.

\subsection{Teaching content}

The teaching content of visual communication design specialty is the aggregation of multidisciplinary comprehensive knowledge. In the specific teaching content, it is difficult to confirm the fixed order and collocation relationship. Therefore, it is rigid in the conventional teaching form, unable to meet the actual needs of society, unable to get rid of the so-called "compressed" curriculum teaching in domestic colleges and universities, and "three". Stage-based talent training. Visual communication design specialty should establish a sound professional layout and reasonable teaching structure, which is the premise of ensuring the teaching content and quality. The teaching content should emphasize the intersection of teaching content and practice. For example, on the basis of traditional professional teaching content, we should increase the intersection of liberal arts, engineering, economy, management, network information and other disciplines, so as to broaden and synthesize the professional orientation, so as to cultivate some visual communication design talents urgently needed by the society in a timely manner. The trained personnel can be competent for the practical work of their major.

\section{Construction of training model for visual communication design talents}

\subsection{Change the traditional education mode and construct the teaching and training system of visual communication design project based on work task}

According to the requirements of the teaching content, it involves carrying out practical research and practice in every link of the design project, letting students collect first-hand information in enterprises or markets in the process of teaching and learning, and carrying out on-site design 
analysis. It is necessary for students to touch and roll on the front line of practice, and participate in the whole process of actual design and development in person, from which they can collect first-hand information and conduct on-site design and analysis. Get exercise, really improve the design ability and practical ability of students, realize the transformation from classroom to professional design training, help students to obtain employment, after repeated simulation training, so that students can acquire practical operation and application ability of design in relevant fields in the training, so as to achieve the application of learning.

\subsection{Focus on the construction of cross-section platform of course content specialty}

In the design of teaching plan, we should emphasize the systematic and Scientology of knowledge system, strengthen the systematic of curriculum integration, make full use of the integration of teaching resources of cross-platform, and design teaching plan according to the principle of broadening the foundation and paying attention to professional integration. Make the teaching plan highlight the requirements of talent training mode and form a distinctive curriculum system. Among them, art courses, humanities courses and engineering courses account for a certain proportion. Specialized courses should emphasize systematic and invulnerability. Some teaching contents should emphasize the integration and infiltration of specialties, so as to facilitate students to master adjacent professional knowledge on the basis of mastering this professional knowledge in an all-round way.

\subsubsection{Knowledge transformation should be based on visual communication specialty.}

Conversion ability is an important ability, which has been mentioned more than once in the curriculum standard. It can convey professional vision to understand the world, convey professional thinking to think about the world, and convey professional language to express the world through vision, which embodies a transformed idea. Knowledge transformation is a kind of transformation. Long-term, lasting process, teachers in daily teaching, through the deduction of some practical problems, to achieve the actual teaching effect, need to work hard on the understanding of visual communication profession. Understanding visual communication profession is to recognize the value of the content of visual communication profession, is to reflect the value of these thinking. Only by understanding the major of visual communication, can we design a good professional activity of visual communication. The author's attempt in this class is based on such a concept.

\subsubsection{Knowledge transformation should be based on the development of professional literacy of visual communication.}

Professional accomplishment of visual communication is often hidden in the invisible places, which requires a pair of wise eyes to explore and find. From this, we can understand that transforming ability is a kind of thinking and problem-solving ability that exists in human itself. It can not be suddenly shown in the form of one or two lessons. This is a long-term and continuous process. Teachers influence a group of students through their own teaching process. Through the smooth transformation of knowledge, dig out the value of thinking in the teaching content of visual communication specialty, as far as possible in each lesson, reflect the improvement of professional accomplishment of visual communication, which is constantly pursued by every teacher, that is, to internalize the "thinking form". A "habit of thinking".

\subsubsection{Knowledge transformation should be based on understanding students' views.}

Designed activities, then in the process of teaching, teachers need to let students really move. 
The action here includes not only hands, but also brains, to mobilize all the senses that can be mobilized, which needs to be carried out on the basis of teachers' understanding of students, design good problems, reflect levels, and let each student. All of them can be improved on the original basis.

\section{Conclusion}

As we all know, due to various reasons, visual communication design education in our country is an extension of graphic design education and some other design specialties. In this context, whether from the perspective of the trend of the development of the discipline itself or the requirement of the social development for the design education, the narrow and closed educational means of art design education in the past can not meet the needs of the development of the times. Therefore, the visual communication design professionals based on knowledge transformation can not meet the needs of the times. The construction of training mode is a further exploration and beneficial supplement to the traditional art and design education. It will play a certain auxiliary role in improving the education level and personnel training of art and design colleges.

\section{Acknowledgement}

Research on Visual Communication Professional Talents Training Model Based on Knowledge Transformation Model /2018 Fujian Youth and Youth Project (Social Science) JAS180733

\section{References}

[1] Henge Bin. Design Education and Cultivation of Creative Thinking [J]. Decoration, 2002 (8).

[2] Li Wei. Constructing Multidimensional Practical Teaching System for Art and Design Major [J]. Decoration, 2006, 164(12).

[3] Nu Angelia. Exploration of innovative education model for students majoring in art and design [J].2008 (5).

[4] Wu Junkie. On Creative Thinking in Design [J]. Packaging Engineering, 2006, 27 (4).

[5] Lin Nanjing. Design Innovation Education [J]. Science and Education Literature Collection, 2010 (5). 